\title{
Effects of percent relief and number of N-R transitions on extinction in relief conditioning
}

\author{
W. J. MILLARD, ALOIS J. JOHNSTON, and PAUL J. WOODS \\ Hollins College, Hollins College, Virginia 24020
}

\begin{abstract}
Forty rats were trained for 10 acquisition and 20 extinction trials in a cold-water relief conditioning apparatus. Two levels of percent relief $(30 \%$ vs. $70 \%)$ and number of transitions from nonrelief $(\mathrm{N})$ to relief $(\mathrm{R})$ trials (1 vs. 3) were factorially combined. Resistance to extinction was found to be a function of percent relief rather than number of $N-R$ transitions.
\end{abstract}

Principles of animal learning are primarily based upon data obtained in appetitive conditioning procedures (Woods, 1974). Behavioral similarities have been observed between analogous appetitive and aversive stimulus operations (e.g., Campbell \& Kraeling, 1953; McAllister \& McAllister, 1967; Millard \& Woods, 1975; Woods, 1967, 1973). Yet, such generality has not been found consistently (Millard \& Woods, 1975; Woods, Markman, Lynch, \& Stokely, 1972). This experiment contributes to our limited knowledge of this problem and examines the relative predictive power of two theories of extinction performance based on either sequential variables (Capaldi, 1964, 1967) or nonsequential variables (Amsel, 1951, 1958) in a relief conditioning analog of Spivey's (1967) small-trial appetitive conditioning procedure.

\section{METHOD}

\section{Subjects}

Naive male Long-Evans descendents $(\mathrm{N}=40)$ were obtained in two shipments from Flow Research, Inc., Dublin, Virginia. The subjects weighed approximately $250 \mathrm{~g}$ at the beginning of the study. Water and food were freely available in each rat's home cage throughout the experiment.

\section{Procedure}

The basic cold-water relief conditioning apparatus has been fully described previously (Woods, 1964). Briefly, it consists of a $168-\mathrm{cm}$ straight alley with two attached tanks. Water temperature of the alley defined the degree of aversiveness; the temperature differential between alley and goal tanks specified the magnitude of relief. Water circulated through reservoirs in

This research was supported by Public Health Service Research Grant M-02883 from the National Institute of Mental Health. A report of this experiment was presented at the meeting of the Eastern Psychological Association, New York, 1975. Requests for reprints should be sent to Paul J. Woods, Department of Psychology, Hollins College, Hollins College, Virginia 24020. W. J. Millard is now at the University of Massachusetts; Alois J. Johnston is now at the University of Pennsylvania. In accordance with a revised taxonomy of instrumental conditioning procedures (after Woods, 1974), the terms "relief" and "relief conditioning" are used to refer to negative reinforcement and escape conditioning, respectively. which the temperature could be maintained within $\pm .5^{\circ} \mathrm{C}$ by presetting Bronwill constant-temperature circulators operating in conjunction with a Forma scientific refrigerated bath.

Underwater photobeams $92 \mathrm{~cm}$ apart and $38 \mathrm{~cm}$ from each end of the alley were used to control clocks equipped with reciprocal faces, enabling the direct reading of overall and midsection speed scores $(10 / \mathrm{sec})$. The experimenter manually started the first clock as a subject was lowered into the alley, while the second clock started when the first photobeam was interrupted. Additionally, the experimenter noted the frequency of competing responses in the alley midsection. Between trials the subjects were housed in a Plexiglas detention cage maintained at approximately $34^{\circ} \mathrm{C}$ by forced-air electric heaters.

The design of this experiment was similar to that described in Spivey's (1967) study of the effects of sequential and nonsequential variables on extinction in a reward training procedure. Two levels of percent relief (30 vs. 70$)$ were factorially combined with two levels of number of transitions from nonrelief (N) to relief (R) trials (1 vs. 3 ). The training trial sequences for the experimental groups and the control group are presented in Table 1.

The alley temperature was maintained at $15^{\circ} \mathrm{C}$ throughout the experiment. Based on prior psychophysical scaling of this aversive dimension, it is known that this temperature is relatively high on the aversive continuum (Woods, Griffith, Page, \& Rodier, 1967). On relief trials subjects in all groups escaped to a goal tank containing water maintained at $40^{\circ} \mathrm{C}$. On nonrelief trials during training and extinction the subjects escaped to a second goal tank containing water at $15^{\circ} \mathrm{C}$ (i.e., $0^{\circ}$ relief magnitude).

For a trial, the experimenter removed the subject from the detention cage and gently lowered it into the starting end of the alley; when it reached the far end of the alley it was placed in the appropriate goal tank (see Table 1). Conditions during extinction were identical for the five groups. The experiment was initially conducted with four subjects in each group and then completely replicated.

Table 1

Sequence of Relief (R) and Nonrelief (N) Trials in Training

\begin{tabular}{|c|c|c|}
\hline \multicolumn{2}{|c|}{ Group } & \multirow[b]{2}{*}{ Trials } \\
\hline $\begin{array}{l}\text { Percent } \\
\text { Relief }\end{array}$ & $\begin{array}{l}\text { N-R Tran- } \\
\text { sitions }\end{array}$ & \\
\hline 30 & 1 & R R N N N N N N N R \\
\hline 30 & 3 & NNR N N R N N R \\
\hline 70 & 1 & R R R N N N R R R \\
\hline 70 & 3 & R N R R R R N R \\
\hline 100 & 0 & R R R R R R R R R \\
\hline
\end{tabular}




\section{RESULTS}

Comparisons of speeds during extinction are difficult to interpret because of the differences among groups in terminal acquisition performance. In the present experiment the mean overall speed scores over the last training trial and the first extinction trial were significantly slower for the two $30 \%$ groups as compared to the two $70 \%$ groups $[F(1,28)=9.62, p<.05]$. The number of N-R transitions factor and the interaction term were not significant $(\mathrm{p}>.10)$. Additionally, the combined $70 \%$ groups were significantly slower than the $100 \%$ control group $[\mathrm{t}(22)=3.62, \mathrm{p}<.05]$. In order to adjust for such differences in acquisition, specialized transforms were required. The absolute overall speed scores were made relative to terminal acquisition and terminal extinction performance by the use of Anderson's (1963) shape-function method. The extinction analyses will focus on the overall speed measure rather than the midsection speeds, for previous reports have indicated the latter are a less sensitive measure of performance (e.g., Woods, 1967; Woods \& Schutz,1965).

Mean shape-function scores are presented in Figure 1 for the first 10 extinction trials. Note that the scores have been combined for the four partial reinforcement groups according to number of N-R transitions (upper panel) and according to percent reinforcement (lower panel). By visual inspection it appears that resistance to extinction was primarily a function of percent reinforcement.

For the statistical analysis a three-factor (percent relief, N-R transitions, and trials) analysis of variance was computed for the shape-function scores. The first extinction trial was omitted in these computations because performance on this trial occurred prior to the first nonrelief trial in extinction. The results of this analysis indicated that the two $30 \%$ groups showed greater resistance to extinction than did the $70 \%$ groups $[F(1,28)=12.72, p<.05]$ and that the number of $\mathrm{N}-\mathrm{R}$ transitions did not significantly affect the rate of extinction $[F(1,28)=1.42, p>.05]$. Consistent with Figure 1, the within-subjects analysis indicated that shape-function scores of the partially reinforced groups decreased over trials in extinction for all groups $[F(8,224)=4.38, p<.05]$ and significantly interacted with the percent relief factor $[F(8,224)=2.47, p<.05]$. All other interactions were not significant. When compared to the $100 \%$ control group, the combined $70 \%$ groups showed greater resistance to extinction $[t(22)=2.15, p<.05]$. Analyses of the competing response data indicated that the frequency was high ihroughout training and extinction but not significantly related to either percent relief or number of N-R transitions.

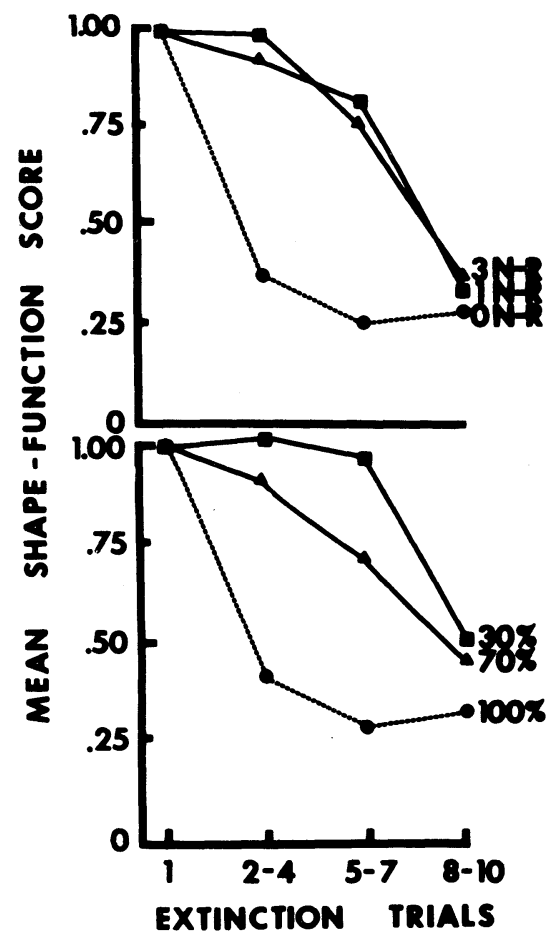

Figure 1. Mean shape-function scores during extinction plotted by number of $N-R$ transitions (upper panel) and percent relief (lower panel).

\section{DISCUSSION}

The results of this experiment indicate that resistance to extinction following a small number of patterned relief conditioning trials is primarily a function of percent relief rather than the number of transitions from nonrelief to relief trials. Therefore, these data are not consistent with the results of Spivey (1967) which indicated that resistance to extinction in an appetitive conditioning procedure increased as a function of the number of $\mathrm{N}-\mathrm{R}$ transitions. Thus, the present results are consistent with Amsel's (1958) nonsequential theory of extinction performance and differ from the outcome predicted by the sequential effects hypothesis (Capaldi, 1964, 1967). The results of the present experiment also differ from those reported by Seybert, Mellgren, Jobe, and Eckert (1974). In their smalltrial shock-escape experiments, it was found that the number of $\mathrm{N}-\mathrm{R}$ transitions and N-length, both stidential variables, affected resistance to extinction. Regretably, differences in procedures (e.g., number of training trials and the aversive stimulus) and the absence of other research reports preclude comments on the origins of these differential results. Clearly, further research is required to establish the relative importance of sequential and nonsequential variables in aversive stimulus conditioning.

\section{REFERENCES}

Amsel, A. A three-factor theory of inhibition: An addition to Hull's two-factor theory. American Psychologist, 1951, 6, 487.

AMSEL, A. The role of frustrative nonreward in noncontinuous reward situations. Psychological Bulletin, 1958, 35, 102-119. 
ANDerson, N. H. Comparison of different populations: Resistance to extinction and transfer. Psychological Review, 1963, 70, 162-179.

Campbell, B. A., \& Kraeling, D. Response strength as a function of drive level and amount of drive reduction. Journal of Experimental Psychology, 1953, 45, 97-101.

CaPaldi, E. J. Effect of $\mathrm{N}$-length, number of different $\mathrm{N}$-lengths, and number of reinforcements on resistance to extinction. Journal of Experimental Psychology, 1964, 68, 230-239.

CAPALDI, E. J. Partial reinforcement: A hypothesis of sequential effects. Psychological Review, 1967, 73, 459-478.

McAllister, W. R., \& McAllister, D. E. Drive and reward in aversive learning. American Journal of Psychology, 1967, 80, 377-383.

Millard, W. J., \& Woods, P. J. Frustrative nonrelief in instrumental escape conditioning. Animal Learning \& Behavior, 1975, 3, 28-32.

Seybert, J. A., Mellgren, R. L., Jobe, J. B., \& Eckert, E. Sequential effects in discrete-trials instrumental escape conditioning. Journal of Experimental Psychology, 1974, $102,473-483$.

SPIVEY, J. E. Resistance to extinction as a function of number of $\mathrm{N}-\mathrm{R}$ transitions and percentage of reinforcement. Journal of Experimental Psychology, 1967, 75, 43-48.
Woops, P. J. Water tank apparatus for instrumental escape conditioning. Psychological Reports, 1964, 14, 167-170.

Woods, P. J. Performance changes in escape conditioning following shifts in the magnitude of reinforcement. Journal of Experimental Psychology, 1967, 75, 487-491.

Woods, P. J. The effects of a sudden reduction in anticipated "relief." Bulletin of the Psychonomic Society, 1973, 1, 5-8.

Woods, P. J. A taxonomy of instrumental conditioning. American Psychologist, 1974, 29, 584-597.

Woods, P. J., Griffith, B. A., PAge, R. P., \& Rodier, P. M. Human responses to various conditions of water temperature. Perception \& Psychophysics, 1967, 2, 157-160.

Woods, P. J., Markman, B. S., Lynch, W. C., \& Stokely, S. N. Partial reinforcement effects in instrumental escape conditioning. Learning and Motivation, 1972, 3, 279-292.

Woods, P. J., \& Schutz, L. J. Performance in instrumental escape conditioning following a shift in drive-stimulus intensity. Proceedings of the 73rd annual convention of the American Psychological Association, 1965, 24, 23.

(Received for publication December 7, 1977.) 